\title{
New Conceptual Handling Systems in Container Terminals
}

\author{
Kap Hwan Kim*, Mai-Ha Thi Phan, Youn Ju Woo \\ Department of Industrial Engineering, Pusan National University, Busan, Korea
}

(Received: June 21, 2012 / Accepted: July 24, 2012)

\begin{abstract}
This paper introduces some of the developments related to the handling equipment in container terminals and various new conceptual handling systems that have been proposed during the last several decades. The basic ideas behind the previous equipment improvements are analyzed to identify future directions that can be used for devising new handling systems. The handling systems in the container terminals include a quayside handling system, transport system, and yard system. In response to the deployment of mega-sized vessels for container transportation systems, productivity improvement has become one of the most urgent issues in the container terminals. This paper analyzes the previous improvements made for achieving higher productivity in the three subsystems of container handling. Some conceptual handling systems are introduced including the linear motor conveyance system (LMCS), automated storage and retrieval systems (AR/RS), overhead grid rail (GRAIL), SPEEDPORT, SuperDock, the automated container system by ZPMC (ACS-ZPMC), and AUTOCON.
\end{abstract}

Keywords: Handling System, Container Terminal, Automation, Survey

* Corresponding Author, E-mail: kapkim@pusan.ac.kr

\section{INTRODUCTION}

The amount of international trade is rapidly increasing as a result of globalization. As the size of a vessel increases, the transportation cost per container decreases, and economy-of-scale holds even in the maritime container transportation. As a result, the sizes of containerships have been steadily increased to reduce transportation costs. The number of containerships with a loading capacity more than 10,000 twenty-foot-equivalent unit (TEUs) is expected to exceed 200 before 2013. Consequently, a higher throughput capacity has been required in international hub ports. Various handling technologies and handling equipment have been introduced to increase the throughput capacities of the international hub container ports.

This study analyzes the handling equipment improvements and attempts to determine the common ideas realized in the improvements for each type of equipment. It is expected that these common ideas may be used for identifying the future directions of new conceptual handling equipment in the container terminals.

Section 2 introduces the most popular logistic processes of container handling in container terminals. Section 3 summarizes the previous improvements in handling equipment to increase the throughput capacity. The new conceptual handling systems proposed to date are introduced in Section 4. Section 5 provides some concluding remarks.

\section{LOGISTIC PROCESSES OF CONTAINER HANDLING}

\subsection{General Logistics Flows in Container Terminals}

In the container terminals, numerous pieces of handling equipment are involved in ship operations and 
hinterland operations. A container has to go through numerous handling steps after it enters a terminal until it is loaded onto a vessel or exits a gate. The various handling activities are introduced in the following paragraphs.

In the container terminals, there are three types of handling operations: ship operations associated with containerships; hinterland operations involving over-the-road trucks, rail transportation, empty container management, and container freight stations; and yard operations involving the storage or retrieval of containers in the yard.

During the ship operations, the containers are discharged from a vessel by using a quay crane (QC) and moved to the yard by using a transporter, which may be a yard truck (YT), straddle carrier (SC), or automated guided vehicle (AGV). They are then placed into a storage bay by a yard crane (YC). During the loading operation, containers are handled in the reverse direction to the discharging operation.

During the hinterland operations, the containers are delivered to a gate by over-the-road trucks and are inspected to determine whether all of their documents are ready and to check for damage. At that time, the storage location in the yard is determined for each outbound container and provided for each inbound container. The truck moves to the designated location, which is called the "transfer point", in a block of container stacks. Then, a YC either receives a container from the truck, which is called a "receiving operation", or delivers a container to the truck, which is called a "delivery operation." For the rail transportation, YTs are usually used to move the inbound and outbound containers between a port container terminal and a rail terminal.

In the yard, containers are handled during the hinterland and ship operations. The operations in this class include remarshaling, which involves changing the positions of containers and managing empty containers.

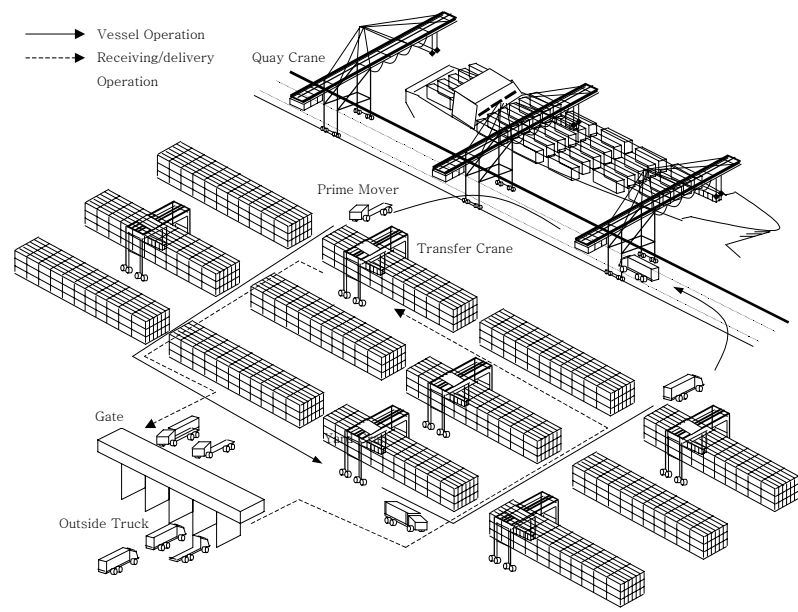

Figure 1. Operations in container terminal (Park, 2003).

\subsection{Various Types of Handling Systems}

There are two types of handling systems in opera- tion all over the world. The first is the "indirect transfer system", in which two different types of handling equipment are used in the yard: YCs and transporters (refer to Figure 2). YCs are used for handling containers in the storage area, and transporters are used for moving containers between QCs and the storage yard. The other type of handling system is the "direct transfer system", in which only one type of handling equipment is used. SCs (Figure 4) and tractors (Figure 3) are examples of the handling equipment. When SCs are used as transporters, the height of the stacks is lower than that in the indirect transfer systems. Therefore, in the case where the storage demand is high and the storage space is insufficient, the indirect transfer system is usually applied.

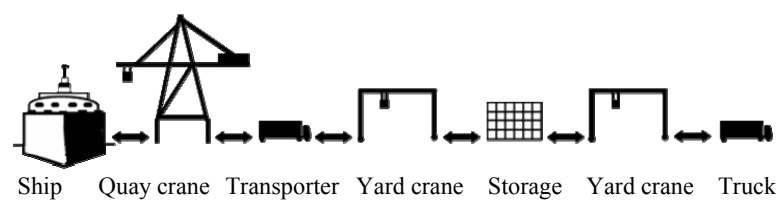

Figure 2. Indirect transfer system.

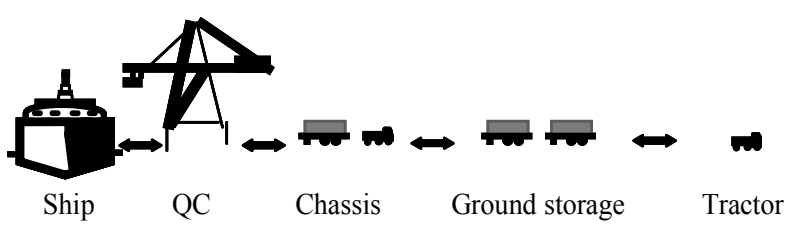

Figure 3. On-chassis system.

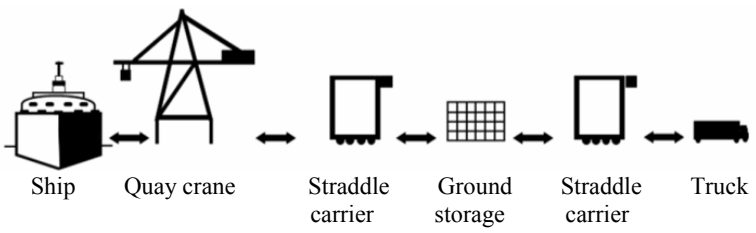

Figure 4. Straddle carrier system.

\section{PREVIOUS IMPROVEMENTS IN HANDLING EQUIPMENT}

This section introduces various improvements in handling equipment that have been made so far to enhance the productivity of handling operations.

\subsection{Quay Cranes}

Figure 5 shows a traditional type of QC, which uses a single trolley for transferring containers between a vessel and YTs. Many studies have been conducted for developing scheduling methods to improve the operational efficiency of QCs (Park, 2003; Jung et al., 2006; Bierwirth and Meisel, 2010; Meisel and Bierwirth, 2011).

Some advanced QCs have been developed to increase the number of lifts per unit time or the number of containers per lift for serving the large vessels that now exist. Figure 6 shows a dual-trolley QC, which uses two 
trolleys, a quayside trolley and a landside trolley, moving on the same track, for transferring containers. Thus, the QC cycle can be divided into two segments. Two trolleys handover containers at a platform. A buffer conveyor moves the containers between the quayside and landside of the platform.

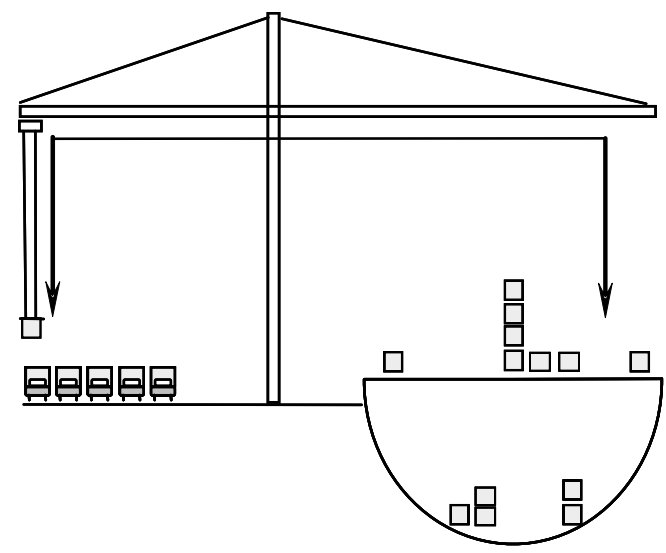

Figure 5. Quay crane with single.

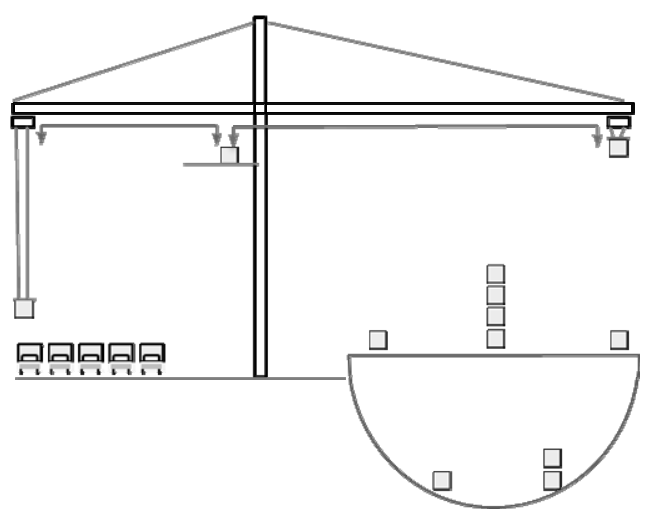

Figure 6. Quay crane with dual trolleys.

SUPERTAINER, which is an idea suggested by the Paceco Corp. (Paceco Corp., 2012), has two trolleys, with a traverser to move containers from one trolley to the other (Figure 7). As a result, the QC cycle is divided into three segments, which further reduces the cycle time.

Figure 8 shows a conceptual design in which two elevators are installed between the quayside trolley and landside trolley. These elevators are responsible for the vertical movement of containers. There are two small conveyors moving outbound containers and inbound containers at different levels. This crane is expected to increase the loading capability to 94 boxes/hour, which is a considerable increase in the productivity compared with the productivity achieved through traditional QCs, which is 38 boxes/hour (Lee et al., 2005).

QCs with a twin-lift spreader can lift two 20-foot containers at the same time. Currently, QCs with a lift- ing capability of two 40-foot containers (tandem lift QC) are popular in newly constructed container terminals. Figure 9 shows a QC being tested that is capable of lifting three 40-foot containers. The productivity of quayside operations has been significantly increased by the application of multilift QCs.

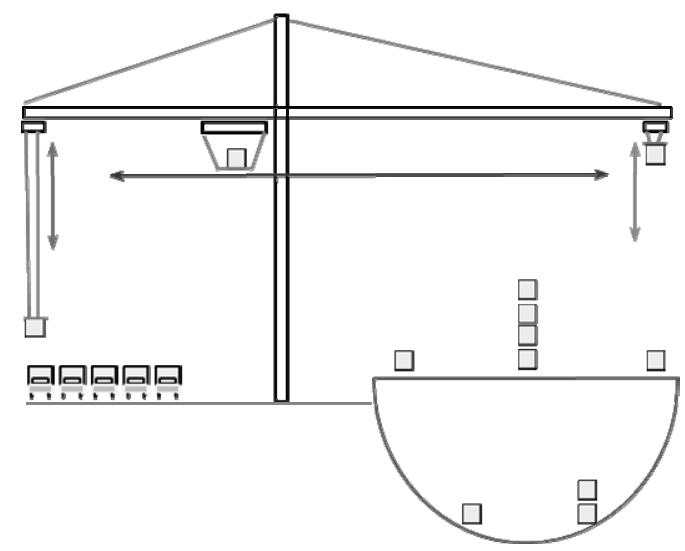

Figure 7. SUPERTAINER ${ }^{\mathrm{TM}}$.

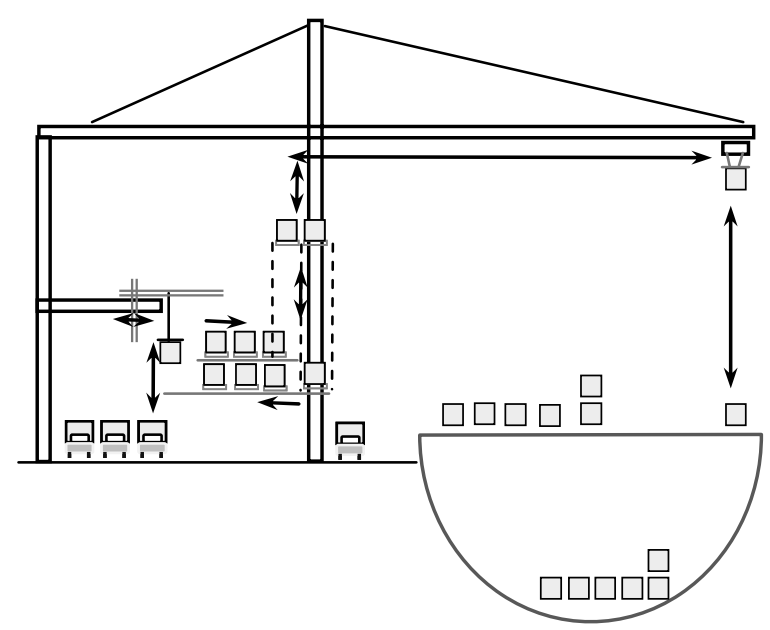

Figure 8. Quay crane with elevators.

Figure 10 shows an indented berth that is in operation at the Ceres Paragon Terminal in Amsterdam. The main idea of this design involves the installation of QCs at both sides of a berth, which allows more QCs to be deployed per berth, significantly increasing the throughput rate. According to the results of an experiment, the throughput rate per berth cannot be increased by more than $20 \%$ by applying the indented berth because of the interference among adjacent QCs and the limited range of vessels that can be served. Chao and Lin (2011) evaluated the performance of advanced QCs in a container terminal. In their paper, they describe four types of QCs: a conventional QC; QC with twin-lift spreader; double trolley QC; and double-sided operation QC system. A two-phase method was developed to select a suitable QC based on a survey of the terminal operators in Kaohsiung port. 


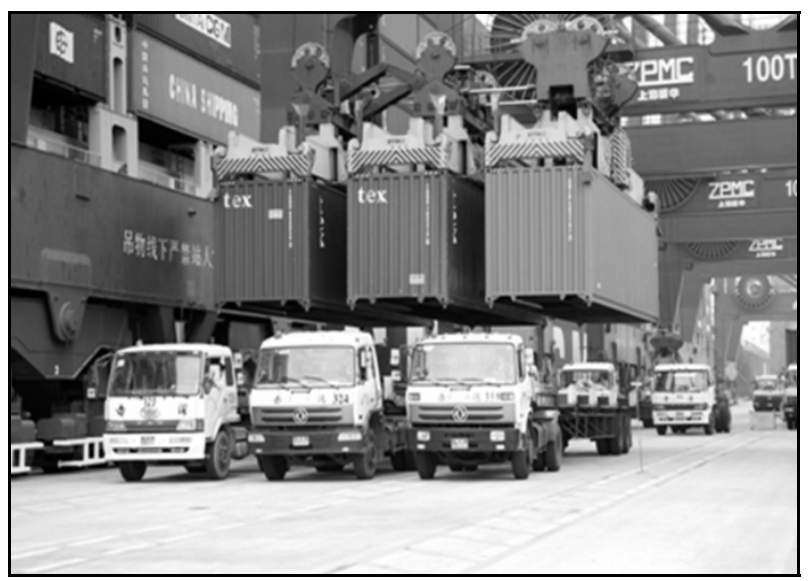

Figure 9. Quay crane with triple lifting capability.

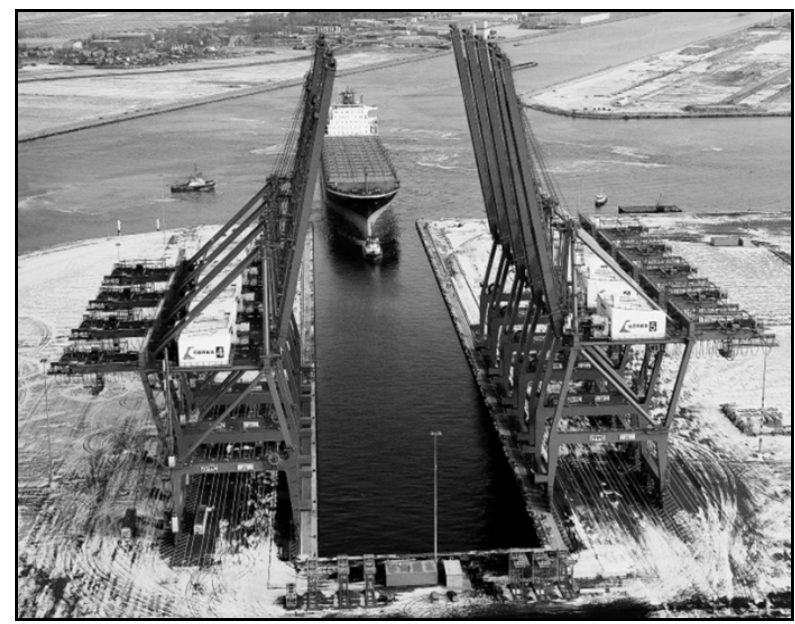

Figure 10. Indented berth.

In summary, various improvements in QC handling equipment have been made to implement the following ideas: 1) the cycle time for a QC needs to be divided into multiple segments to reduce it; 2) the multi-lifting capability needs to be applied to QCs to increase their throughput rate; 3) more QCs need to be deployed to increase the QC throughput rate per berth.

\subsection{Transport Systems}

As far as the indirect transfer system is concerned, the most popular transport equipment is a truck consisting of a tractor and chassis. The automated version of the truck is the automated guided vehicle (AGV) (Figure 11a). One of the disadvantages of using trucks or AGVs is the possibility that a crane or transporter may have to wait for the arrival of the other type of equipment for the handover of a container. Vis (2006) provided a good literature survey concerning the design and operation of AGVs. In relation to the efficient operation of AGVs in container terminals, there have been many studies on dispatching (Bish et al., 2001, 2005; Kim and Bae, 2004; Briskorn et al., 2006; $\mathrm{Ng}$ et al., 2007; Lee et al., 2009;
Angeloudis and Bell, 2010; Nguyen and Kim, 2010).

Another type of transporter is a shuttle carrier or SC (Figure 11b). Shuttle carriers can pick up containers directly from the floor and put them down on the floor, which removes the need for the handover operation. Vis and Harika (2004) and Bae et al. (2011) compared the performances of vehicles with pickup capability and AGVs.

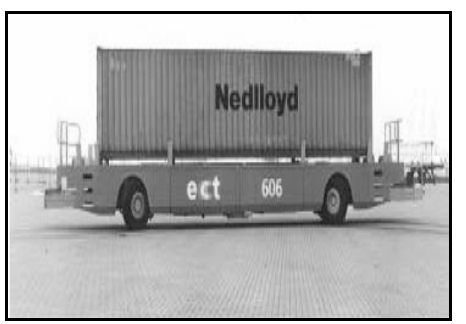

(a)

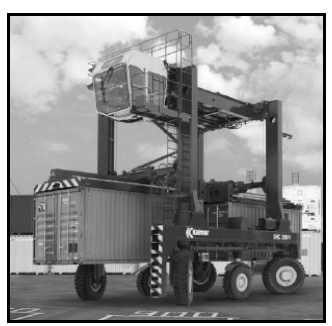

(b)

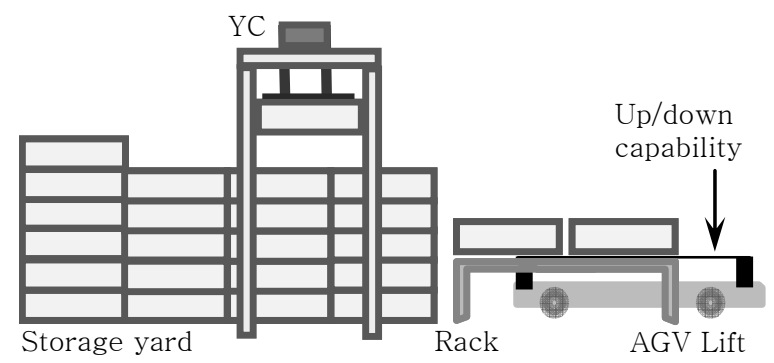

(c)

Figure 11. Various types of transporters, (a) Automated guided vehicle (AGV), (b) shuttle carrier, (c) $\mathrm{AGV}$ with lifting rack. YC: yard crane.

Even when AGVs are used for transporting containers, the crane operation may be decoupled from the transporter operation by installing racks at the end of yard blocks so that cranes or AGVs can release containers onto the rack even before the other equipment arrives at the handover position. Comparison of various types of transporters indicates that the productivity of a shuttle carrier or AGV with a lifting rack was twice that of an AGV (Saanen, 2003; Siroky, 2011).

The transport system was improved by removing the need for handover with cranes for transferring containers, as explained above. In addition, multi-loading capabilities were added to new conceptual transporters (Figure 12). The cassettes are steel platforms that are detachable from an AGV, on which containers can be located. A possible advantage of cassettes is that they can be used as a buffer station, which removes the necessity of handing over containers between cranes and transporters. The cassette system was developed by two European Union sponsored projects, Improved Port Ship Interface (IPSI) and INTEGRATION: Integration of Sea Land Technologies (Henesey et al., 2006). There have been several studies on dispatching multiload AGVs in container terminals (Grunow et al., 2004). 

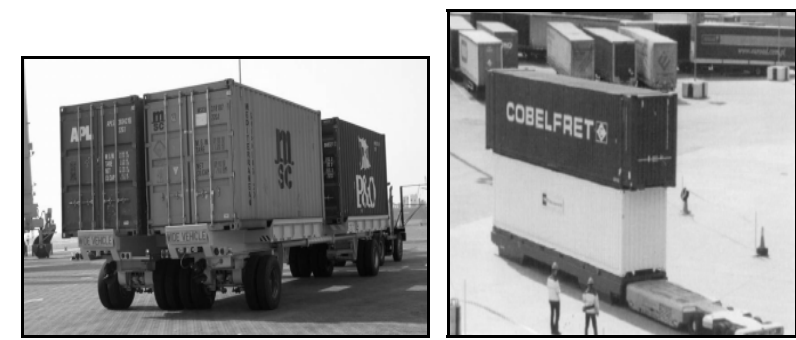

Figure 12. Transporters with multiloading capabilities. Right panel is cassette system.

In addition to improving the hardware of transporters, much effort has been made to improve the operational efficiency by using advanced operation rules or algorithms. For automated transporters, the efficient dispatching, routing, scheduling, and traffic control methods (Evers and Koppers, 1996) have been developed and applied in practice. For AGVs, in particular, a closed loop guide path network, in which vehicles move along a loop type of guide path, has been used for a long time. It has been improved to provide more shortcuts for reducing the travel distance of vehicles, which is called a guide path of the cross lane type. Recently, pooling strategies have successfully been applied in many container terminals. A pool is constructed by including multiple QCs. All the vehicles are shared by all the QCs in the pool. The vehicles in a pool may serve any QC in the pool. By applying the pooling system, if an efficient dispatching algorithm is provided, the efficiency of the vehicle operation is expected to improve.

\subsection{Storage Systems}

As the storage space requirement has increased, the stacks have become higher and higher. In the early days of container terminals, on-chassis systems or reach stackers were the major handling systems. The height of stacks was 1-3 tiers. Then, the SCs became popular. As a result, the height of stacks became 2-3 tiers. Now, YCs are the most popular equipment in yards and the height of stacks has become 4-6 tiers. As the stacks grow higher, more attention has to be paid to rehandling operations.

Various algorithms and operational rules have been developed to minimize the rehandling operations. Rehandling operations for outbound containers mainly arise because of their weight (Kim et al., 2000; Kang et al., 2006; Kim and Hong, 2006; Imai et al., 2006; Caserta et al., 2011; Zhang et al., 2010). Rehandling operations for inbound containers come from the randomness of the container retrieval sequence by over-the-road trucks or trains (Kim, 1997; Lee and Lee, 2010; Zhao and Goodchild, 2010; Sauri and Martin, 2011). To reduce the rehandling operations, remarshaling operations can be performed in advance before the containers are retrieved (Lee and Hsu, 2007; Lee and Chao, 2009).

Related to handling capacities, the throughput ca- pacity requirement has been steadily increased. This trend goes along with the increase in the size of vessels. For example, the Europe Container Terminal (ECT), which is the first automated container terminal, installed a single automated yard crane per block. After this, Container Terminal Altenwerder (CTA) in Hamburg installed two YCs in a block. However, they attempted to minimize the interference between the two cranes by making their sizes different so that they can cross each other.

Container Terminal Burchardkai (CTB) in Hamburg is now constructing a new storage system, in which three yard cranes will be installed in the same block. The overall trend for yard systems is that the storage density has become higher and more cranes have been deployed in the same storage area to increase the throughput rate. However, interference among the cranes has been the operational problem to overcome. To improve the efficiency of YCs, various operation rules or algorithms have been developed (Carlo and Vis, 2008; Vis and Carlo, 2010; Guo et al., 2011; Park et al., 2011; Li et al., 2012).

\subsection{Criteria for Designing Future Handling Systems}

The improvement trends in the handling systems for container terminals are summarized in Table 1. The contents in Table 1 were already explained in subsections 3.1-3.3. In addition to the criteria related to the performance, there are other criteria that must be considered during the design stage of a new conceptual container terminal. These are listed in Table 2. The first consideration is flexibility. The proposed handling system should be applicable with minor modifications, even when the container flow pattern is different or when the logistics environment changes. When the handling system is installed, it should be possible to easily adapt it to the continuously changing situation of the terminal. Of course, the cost, including not only the construction cost but also the operation cost, is the second consideration. In addition, the new system needs to be environmentally friendly. That is, it should consume as little energy and emit as little $\mathrm{CO}_{2}$ as possible (Geerlings and Duin, 2011). Finally, the new system should have

Table 1. Developments to improve performance

\begin{tabular}{|c|l|}
\hline Classification & \multicolumn{1}{|c|}{ Previous improvements } \\
\hline \hline $\begin{array}{c}\text { Quayside } \\
\text { operation }\end{array}$ & $\begin{array}{l}\text { Cycle time division } \\
\text { Multilifting } \\
\text { Denser deployment of cranes }\end{array}$ \\
\hline Transporters & $\begin{array}{l}\text { Lower time loss for handover of containers } \\
\text { Multilifting } \\
\text { More efficient operation for transporters }\end{array}$ \\
\hline Storage & $\begin{array}{l}\text { Higher storage density with a small number } \\
\text { of rehandles } \\
\text { More cranes for higher throughput capacities } \\
\text { with a low level of interference }\end{array}$ \\
\hline
\end{tabular}


the capability to recover in a short time from an abnormal state resulting from an unexpected disturbance and should allow easy maintenance activities.

Table 2. Strategic considerations

\begin{tabular}{|c|c|}
\hline Classification & Criteria \\
\hline Flexibility & $\begin{array}{l}\text { Applicability to various situations with the } \\
\text { least modification } \\
\text { Adaptability to changing situation }\end{array}$ \\
\hline Cost & $\begin{array}{l}\text { Investment } \\
\text { Operation cost }\end{array}$ \\
\hline Environment & $\begin{array}{l}\text { Energy consumption } \\
\mathrm{CO}_{2} \text { emission }\end{array}$ \\
\hline Technology & Technological feasibility \\
\hline $\begin{array}{l}\text { Robustness } \\
\text { to failures }\end{array}$ & $\begin{array}{l}\text { Maintainability } \\
\text { Recoverability from an abnormal state }\end{array}$ \\
\hline
\end{tabular}

\section{NEW CONCEPTUAL HANDLING SYSTEMS}

This section introduces the new conceptual handling systems for container terminals, which include the linear motor conveyance system (LMCS), automated storage and retrieval systems (AR/RS), overhead grid rail (GRAIL), SPEEDPORT, SuperDock, an automated container system by ZPMC (ACS-ZPMC), and AUTO$\mathrm{CON}$. The functions of some of these, including the LMCS, AS/RS, and ACS-ZPMC, were verified by constructing and testing a prototype system. This paper introduces only the representative innovative container handling systems which we could find through the literature survey.

\subsection{Linear Motor Conveyance System}

Figure 13 shows the yard and driving area for the transporters in the LMCS. The unique features of this system are that shuttles powered by a linear motor are used as transporters and move on rails on a fixed guide path network.

The linear motor technology has been used for a long time in various industrial fields. Thus, the LMCS may be developed by using the proven technologies. Other advantages of the LMCS include the high positioning accuracy, high reliability, and robustness of the handling equipment. In addition, the LMCS may be considered an environmentally friendly system because it uses electricity instead of the diesel oil used by trucks or AGVs.

One of the disadvantages of the LMCS is the high investment cost for the initial construction. Moreover, because there are a limited number of routes for shuttles, the routing flexibility of the transporters is relatively low compared with truck- or AGV-based systems (Ioannou et al., 2000a).

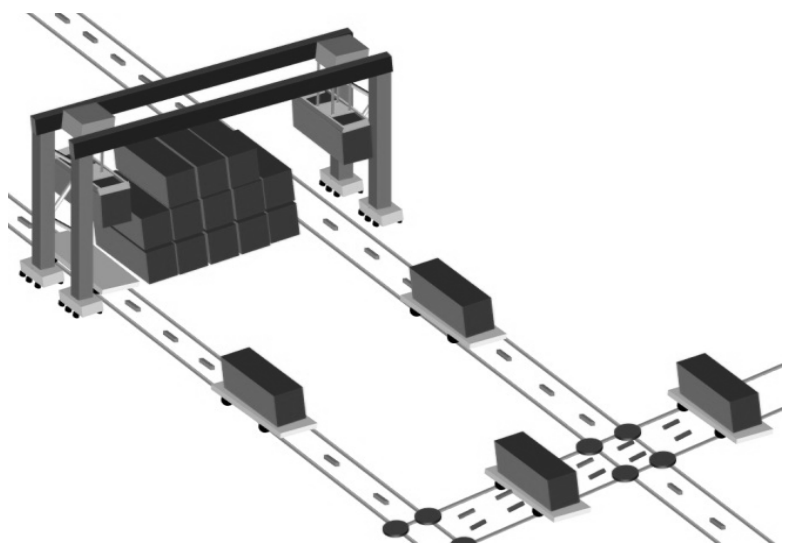

Figure 13. Shuttles and rails of linear motor conveyance system.

\subsection{Automated Storage and Retrieval Systems}

The two major components of AS/RS are the storage and retrieval machine (SRM) and the storage racks. Figure 14 shows part of an AS/RS. There is a pickup/ delivery station at the entrance of each aisle. The station is usually located at one end on the lowest level of each aisle.

The AS/RS has the advantages of providing a highdensity storage capacity, high throughput rate, and random access for a target container, without rehandling operations. It is possible to build this system on a small area of ground, and then easily add storage capacity by increasing the number of floors. This would be useful when the space is limited and costly. However, the construction cost is high and a breakdown of an SRM may block all the operations in the corresponding aisle, for which some recovering measure must be provided.

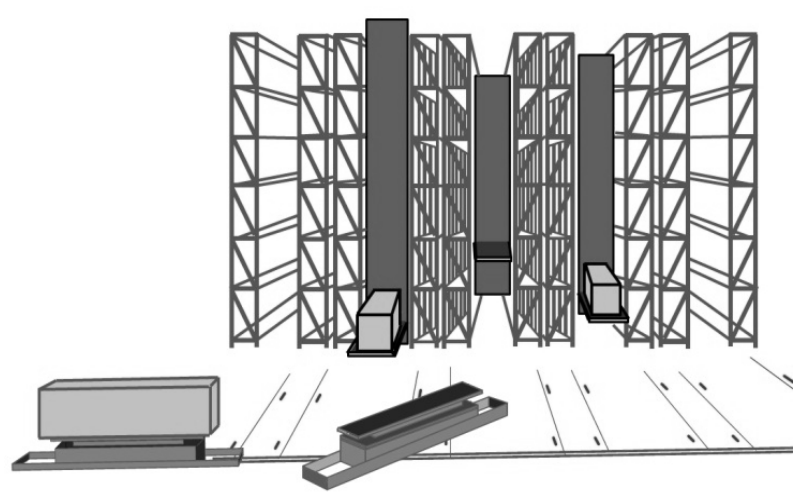

Figure 14. Storage racks and transporters in automated storage and retrieval systems.

A prototype of the high stacking system (HSS) (Choi and Ha, 2005), which is a variant of AS/RS, has been installed and tested by EZ-INDUS in Korea. This HSS used a shuttle at each aisle and an elevator at each row of the openings in each aisle to improve the throughput rate of the system. 


\subsection{Overhead Grid Rail (GRAIL)}

The overhead grid rail system, called GRAIL, was developed by Sea-Land in 1988. The main pieces of equipment are electric shuttles that are used for the storage operations in the yard and for the delivery operations between the yard and quayside. Figure 15 shows an overview of the GRAIL (Brickner et al., 1990). The shuttles move above the stacks and carry containers via the overhead rails. The switching mechanisms at the end of each rail allow the shuttles to move from one rail to the next. In addition, it is possible for shuttles to move containers directly between the quay and the rail station by extending the rail from the quayside to the rail station.

The connection points between QCs and shuttles are the elevated automated platforms below the QCs, where the QC operation and shuttle operation are decoupled, that is, QCs pick up or place containers without caring about shuttle arrivals, and the shuttles put down or pick up containers without waiting for the arrival of QCs. This decupling reduces the waiting time for equipment. Note that the driving area for the shuttles is moved to the overhead space. This makes it possible to save the space wasted on aisles and avoid the interference of container transporters with container stacks on the ground and with the traffic of manually operated trucks. However, a more complicated control system should be provided and a high investment cost would be required.

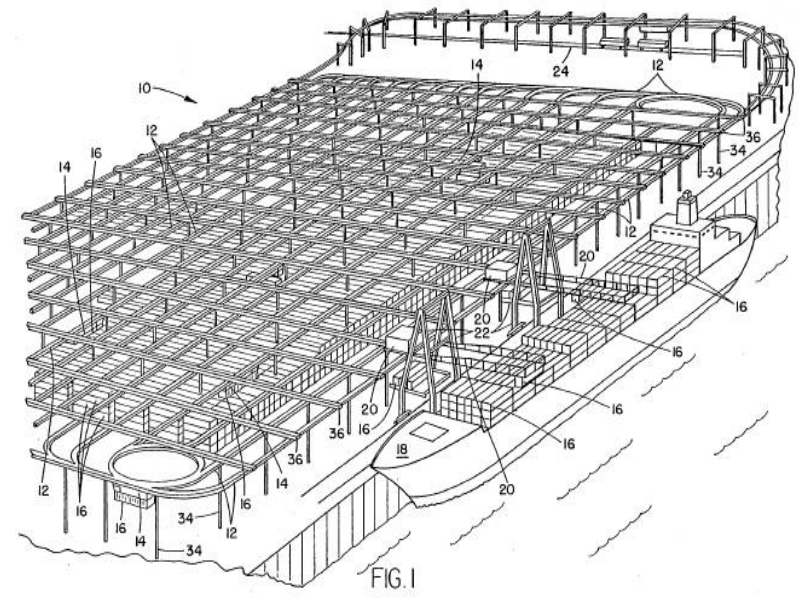

Figure 15. Overview of overhead grid rail (GRAIL) system (Brickner et al., 1990).

Ioannou et al. (2000b) studied the GRAIL. They proposed this system as an attractive solution for places where land is limited and expensive and high terminal productivity is required. Liu et al. (2002) analyzed and evaluated four different automated container terminal concepts: AGVs, LMCS, an overhead grid rail system, and a high-rise AS/RS. They used simulation models with the same operation scenario to evaluate their performances and associated costs.

\subsection{SPEEDPORT}

SPEEDPORT was introduced by the ACTA Maritime Development Corporation. The concept of SPEED PORT is the extension of the rails in the GRAIL system over the ship for the ship operation. The main piece of equipment is the spider shown in Figure 16, which has the functions of both the truck and the shuttle in the GRAIL. Each spider is self-propelled and travels on a network of overhead beams and elevated ground rails.

Figure 17 shows a discharging operation cycle in the SPEEDPORT system. Above the yard or ship, a spider traverses under the overhead beams by using an overhead carriage. During its travel in the direction of the length of the terminal, the spider travels on ground wheels, which guide the spider on elevated ground rails.

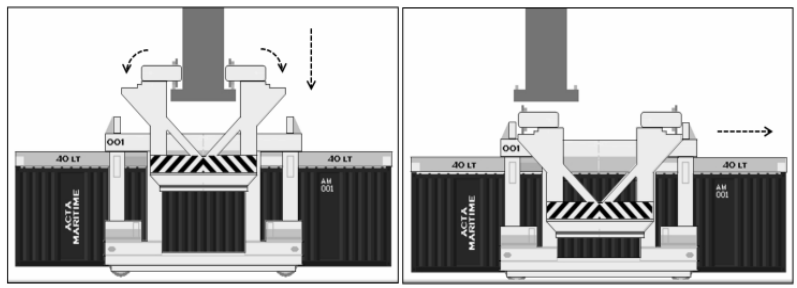

Figure 16. Empty spider proceeds to assigned overhead beam (http://www.actamaritime.com).

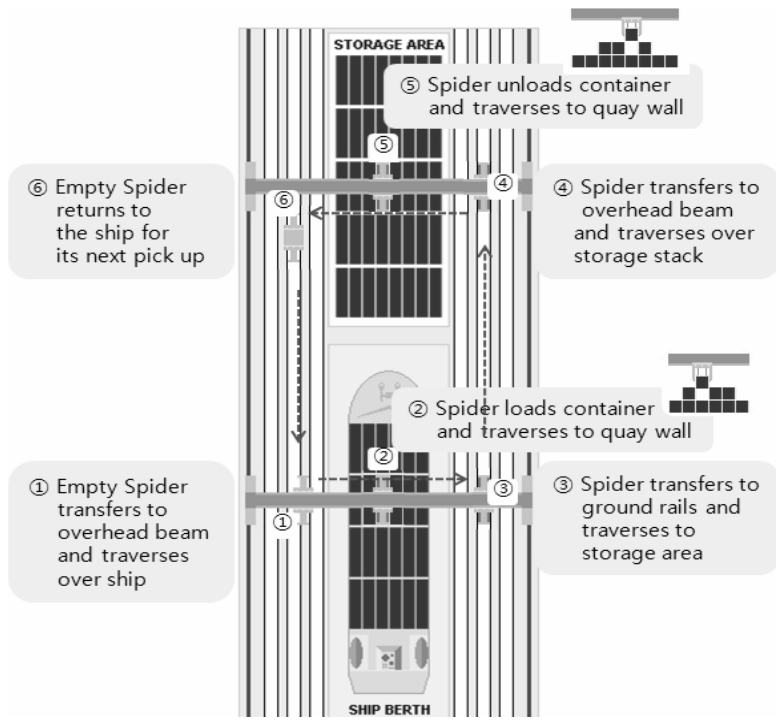

Figure 17. Discharge operation cycle in SPEEDPORT system.

This system can reduce the handover time between cranes and transporters in a system employing the traditional QCs and YCs by using spiders, which can perform the functions of both cranes and trucks. In addition, a large number of spiders can work together at the same ship bay or at the same yard bay, which may contribute to a considerable increase in the throughput rate of the ship operation of the system.

However, the cost of constructing the structure and 
spiders is expected to be very high. Moreover, there are some technical issues involving its lack of flexibility when dealing with different size vessels or different types of ships. Spiders must carry enough cable to reach deep into the cells of large container ships, which may make the spider heavy.

\subsection{Automated Container System (ZPMC)}

ZPMC (Shanghai Zhenhua Heavy Industry Co. Ltd, China) has developed a new automated container system with a new transport system, as shown in Figure 18. A fixed rail-guided transfer system was introduced at the apron area, as shown in Figure 19.

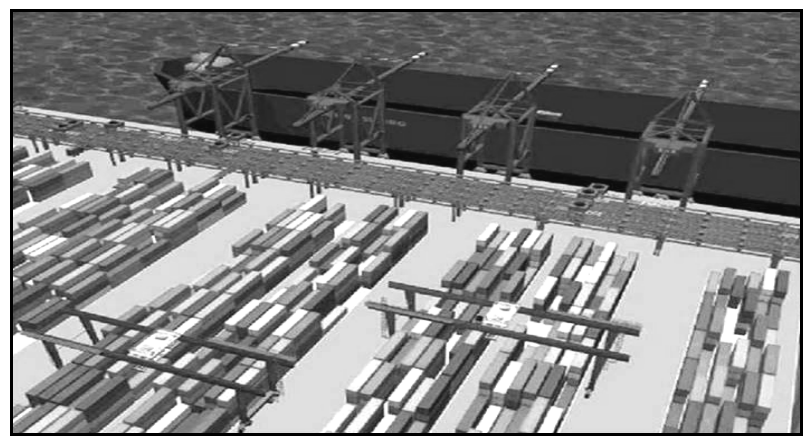

Figure 18. New transfer system by ZPMC (www.ZPMC.com).

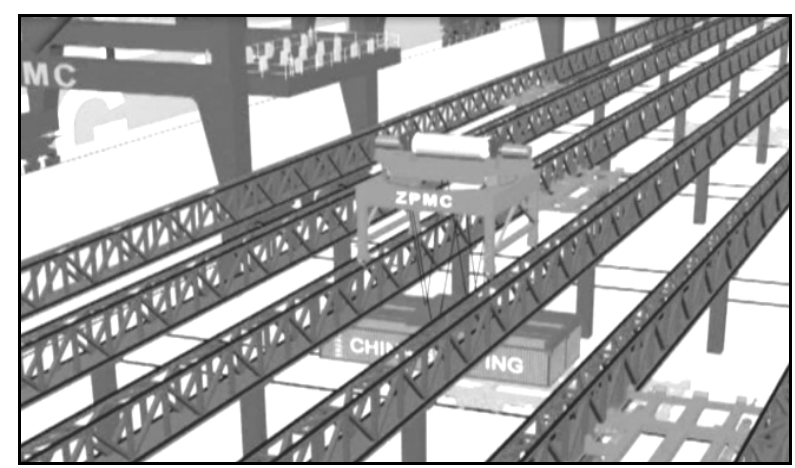

Figure 19. Overview of automated container system by ZPMC (www.ZPMC.com).

As shown in Figure 19, all equipment is designed to handle twin 40 -feet containers. The flat cars run on rails on two levels: one elevated rail is installed in the same direction as that of the QC rails, and the other rail is laid out on the ground in the direction perpendicular to the quay. More tiers can be added to the upper rail if necessary. After a QC discharges a container on an upper flat car, it runs to a pre-specified position to transfer the container to a rail-mounted crane (RMGC). The RMGC picks up the container and turns it by $90^{\circ}$ to change its direction. Then, the RMGC places it on the ground flat car. The ground flat car carries the container from the transfer structure to an RMGC in the yard. The scheduling problem needs to be studied to synchronize the movements of all the related equipment, which may be complicated (Tian et al., 2011).

ZPMC made a test bed on Changxing Island, where this system has been installed and tested to prove the technologies for realizing the concept. The system is known to have the following advantages: the control of transporters becomes simplified compared with that in AGV systems; the system is more reliable and easier to maintain than the traditional automated container terminals in Europe; and because it uses electricity only, it is an environmentally friendly system. However, the high construction cost and less flexible routing of flat cars may be considered its disadvantages. In addition, there is a possibility that the flat cars moving between the yard and apron may become a bottleneck for the system.

\subsection{SuperDock}

The SuperDock concept was derived from the need for an economically and environmentally superior container terminal at the ports of Los Angeles and Long Beach (Alba and Risemberg, 2011). Figure 20 shows that this system contains powered rail conveyor and universal stack systems, with a long berth and numerous QCs. On the other side, a rail is provided for trains. This makes it possible for trains to access the stacking system directly, which should contribute to the modal change from road to rail transportation.

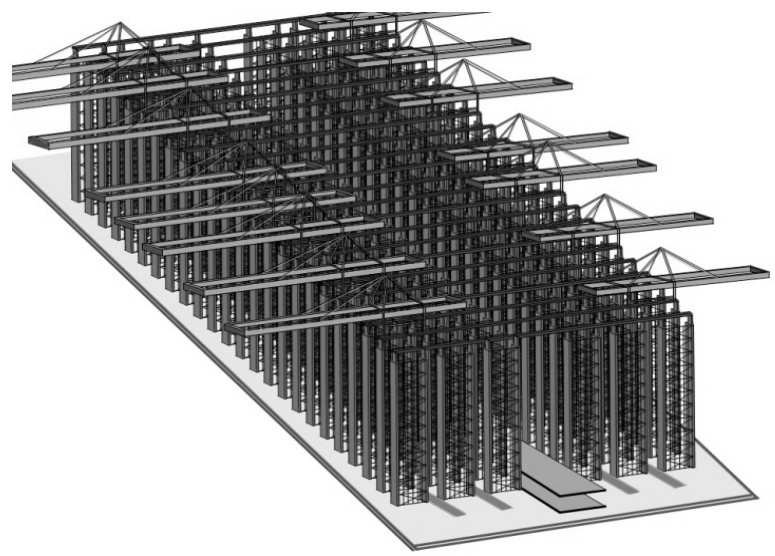

Figure 20. Overview of SuperDock system.

The application of the SuperDock system would decrease the air, noise, and traffic pollution resulting from the congestion during intermodal container transshipments between vessels and rails or trucks. It is also expected to reduce the operating costs and increase transshipment performances. Alba (2012) estimates that the system will eliminate approximately $70 \%$ of all truck deliveries to and from the port. In spite of these advantages, the high construction cost and complicated controls are expected to be its disadvantages. When analyzing the SuperDock system, David Alba, a former port logistics supervisor, asserts that the costs would undoutedly run into billions. However, the immediate yield 
would be tens of thousands of clean, green, and highpaying jobs (Kalfayan, 2011).

\subsection{AUTOCON}

AUTOCON is based on the concept of using linear motor technology for the automated transfer of containers. This system was proposed by The Center for Logistics Technology and Freight Transport Market Research, The Korea Transport Institute (AUTOCON systems, 2012). It would also be applicable to underground freight transportation. An overview of the AUTOCON system is shown in Figure 21. The equipment used to transfer containers includes loop-type storage structures, fixed guide path rails, and linear motor platforms. The platforms move like an accordion, which makes non-stop transportation possible. Vessels and trains can be served at the side of the stacking structure, as shown in Figure 22.

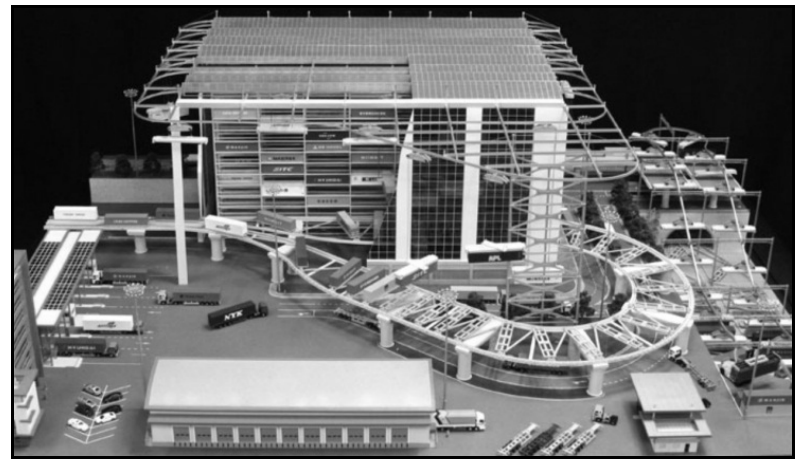

Figure 21. Overview of AUTOCON system 1 (http://blog. naver.com/germangray?Redirect $=\log \& \log$ No $=90130701325$ ).

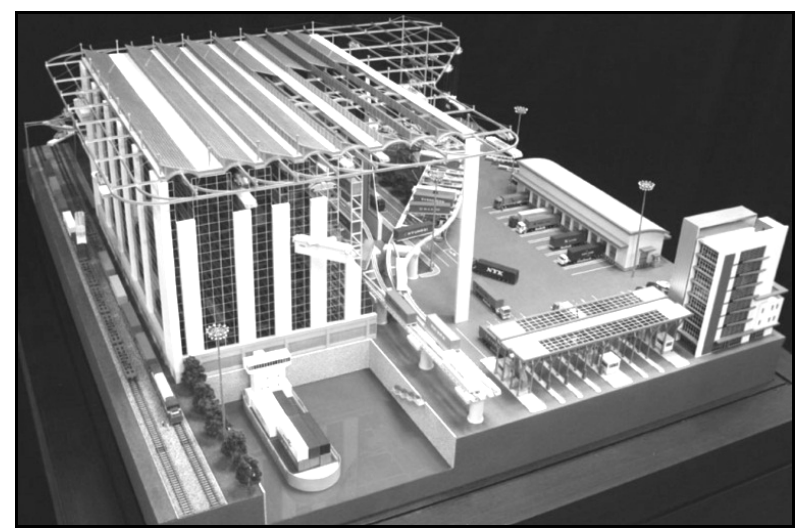

Figure 22. Overview of AUTOCON system 2 (http://blog. naver.com/germangray?Redirect $=\log \& \log \mathrm{No}$ $=90130701325$ ).

It was estimated that if the AUTOCON system was used to carry out all the container transportation on the Seoul-Busan axis, it would save about 340 billion KRW in inland container transport costs and slash $\mathrm{CO}_{2}$ emissions by 183,000 tons (Roh, 2011). This system may be applied to port container terminals, as well as to inland container terminals and mega hub rail terminals. Moreover, this is an environmentally friendly system. However, the construction cost may be very high.

\section{CONCLUSION}

This paper reviewed various improvements made in the handling systems for container terminals during the last several decades. It was found that the major characteristics of the improvements in the quayside systems include the areas of 1) cycle time division, 2) multilifting, and 3) denser crane deployment. For the transport systems, the improvements were 1) lower time loss for the handover of containers, 2) multilifting, and 3) more efficient transporter operations. The storage systems have been improved in the direction of 1) higher storage density with a small number of rehandles and 2) more cranes for higher throughput capacities with a low level of interference.

New conceptual handling systems have been introduced, including the LMCS, AS/RS, GRAIL, SPEED PORT, ACS-ZPMC, SuperDock, and AUTOCON.

All the proposed systems have been designed to use electricity as a power source implementing the idea that $\mathrm{CO}_{2}$ emissions and air pollution should be minimized. Furthermore, independent transporters are not used in GRAIL, SPEEDPORT, AUTOCON, and SuperDock. Some of the new systems do not need independent QCs.

By merging the functions of transporting, stacking, loading, and unloading, the time for transferring containers between adjacent subsystems may be reduced, and as a result, the productivity of the entire handling system can be increased. However, in every case, the construction cost is very high. In some cases, because of the limited rail network, the flexibility during the operation becomes lower, which may limit the throughput rate of the entire system.

However, it is well known that the size of vessels has to steadily increase because of economy-of-scale and globalization. It is also known that the traditional handling systems may not be able to satisfy the required level of service in terms of the throughput rate and storage space capacity. Therefore, new conceptual container terminals should be developed to satisfy all the future requirements. Further studies should be conducted to specify and design in detail each of the conceptual terminal systems introduced in this paper.

\section{ACKNOWLEDGMENTS}

This study is supported by the Post BK-21 Project of Ministry of Education, Science and Technology of Korea and supported by Pusan National University Research Grant for two years. 


\section{REFERENCES}

Alba, D. (2012), The GRID project (green rail intelligent development), Planet Forward, The George Washington University, Washington, DC. http://planetfor ward.org/idea/the-grid-project-green-rail-intelligentdevelopment/.

Alba, D. J. and Resenberg, R. (2011), How would the ports stack up? Los Angeles Business Journal. http://www. labusinessjournal.com/news/2011/sep/05/how-wou ld-ports-stack/.

Angeloudis, P. and Bell, M. G. H. (2010), An uncertaintyaware AGV assignment algorithm for automated container terminals, Transportation Research Part E: Logistics and Transportation Review, 46(3), 354366.

AUTOCON system (2011), Division for Logistics Technology and Freight Transport Market Research, The Korea Transport Institute, http://blog.naver. com/germangray? Redirect $=\log \& \operatorname{logNo}=901307$ 01325 .

Bae, H. Y., Choe, R., Park, T., and Ryu, K. R. (2011), Comparison of operations of AGVs and ALVs in an automated container terminal, Journal of Intelligent Manufacturing, 22(3), 413-426.

Bierwirth, C. and Meisel, F. (2010), A survey of berth allocation and quay crane scheduling problems in container terminals, European Journal of Operational Research, 202(3), 615-627.

Bish, E. K., Chen, F. Y., Leong, T. Y., Nelson, B. L., Ng, J. W. C., and Simchi-Levi, D. (2005), Dispatching vehicles in a mega container terminal, $O R$ Spectrum, 27(4), 491-506.

Bish, E. K., Leong, T. Y., Li, C. L., Ng, J. W. C., and Simchi-Levi, D. (2001), Analysis of a new vehicle scheduling and location problem, Naval Research Logistics, 48(5), 363-385.

Brickner, L. R., Chou, R. C., Chun, M. D., Radzikowski, P., and von Isenburg, C. (1990), Grid rail container transport and storage system, US Patent No. 4973 219, Sea-Land Corporation, Elizabeth, NJ.

Briskorn, D., Drexl, A., and Hartmann, S. (2006), Inventory-based dispatching of automated guided vehicles on container terminals, OR Spectrum, 28(4), 611-630.

Carlo, H. J. and Vis, I. F. A. (2008), Routing New Types of Stacking Crane Configurations at Container Terminals, Progress in Material Handling Research: Proceedings of the 10th International Material Handling Research Colloquium, Dortmund, Germany, 55-70.

Caserta, M., Voss, S., and Sniedovich, M. (2011), Applying the corridor method to a blocks relocation problem, OR Spectrum, 33(4), 915-929.

Chao, S.-L. and Lin, Y.-J. (2011), Evaluating advanced quay cranes in container terminals, Transportation Research Part E: Logistics and Transportation Review, 47(4), 432-445.
Choi, S. H. and Ha, T. Y. (2005), A study on high-efficiency yard handling system for next generation port, Ocean Policy Research, 20(2), 81-126.

Evers, J. J. M. and Koppers, S. A. J. (1996), Automated guided vehicle traffic control at a container terminal, Transportation Research Part A: Policy and Practice, 30(1), 21-34.

Geerlings, H. and van Duin, R. (2011), A new method for assessing $\mathrm{CO}_{2}$-emissions from container terminals: a promising approach applied in Rotterdam, Journal of Cleaner Production, 19(6/7), 657-666.

Grunow, M., Gunther, H.-O., and Lehmann, M. (2004), Dispatching multi-load AGVs in highly automated seaport container terminals, OR Spectrum, 26(2), 211-235.

Guo, X., Huang, S. Y., Hsu, W. J., and Low, M. Y. H. (2011), Dynamic yard crane dispatching in container terminals with predicted vehicle arrival information, Advanced Engineering Informatics, 25 (3), 472-484.

Henesey, L., Davidsson, P., and Persson, J. A. (2006), Comparison and evaluation of two automated guided vehicle systems in the transshipment of containers at a container terminal, Proceedings of the 5th International Conference on Computer Applications and Information Technology in the Maritime Industries, Leiden, Netherlands, 54-64.

Imai, A., Sasaki, K., Nishimura, E., and Papadimitriou, S. (2006), Multi-objective simultaneous stowage and load planning for a container ship with container rehandle in yard stacks, European Journal of Operational Research, 171(2), 373-389.

Ioannou, P. A., Kosmatopoulos, E. B., Jula, H., Collinge, A., Liu, C.-I., Asef-Vaziri, A., and Dougherty, E. J. (2000a), Cargo handling technologies, Final Report-Task 1.2.3.2, Center for Commercial Deployment of Transportation Technologies, Los Angeles, CA.

Ioannou, P. A., Kosmatopoulos, E. B., Vukadinovic, K., Liu, C.-I., Pourmohammadi, H., and Dougherty, E. J. (2000b), Real time testing and verification of loading and unloading algorithms using grid rail (GR), Final Report-Task 1.2.6.2, Center for Commercial Deployment of Transportation Technologies, Los Angeles, CA.

Jung, D. H., Park, Y.-M., Lee, B. K., Kim, K. H., and Ryu, K. R. (2006), A quay crane scheduling method considering interference of yard cranes in container terminals, MICAI 2006: Advances in Artificial Intelligence, Lecture Notes in Computer Science, 4293, 461-471.

Kalfayan, E. (2011), Game changing goods movement crane innovation: key element of GRID project, Moving Southern California, 6(5), 4-5, http://www. thetransitcoalition.us/NewsLetterPaper/NL201105 v11a.pdf.

Kang, J., Ryu, K. R., and Kim, K. H. (2006), Deriving 
stacking strategies for export containers with uncertain weight information, Journal of Intelligent Manufacturing, 17(4), 399-410.

Kim, K. H. (1997), Evaluation of the number of rehandles in container yards, Computers and Industrial Engineering, 32(4), 701-711.

Kim, K. H. and Bae, J. W. (2004), A look-ahead dispatching method for automated guided vehicles in automated port container terminals, Transportation Science, 38(2), 224-234.

Kim, K. H. and Hong, G.-P. (2006), A heuristic rule for relocating blocks, Computers and Operations Research, 33(4), 940-954.

Kim, K. H., Park, Y. M., and Ryu, K.-R. (2000), Deriving decision rules to locate export containers in container yards, European Journal of Operational Research, 124(1), 89-101.

Lee, D.-H., Cao, J. X., Shi, Q., and Chen, J. H. (2009), A heuristic algorithm for yard truck scheduling and storage allocation problems, Transportation Research Part E: Logistics and Transportation Review, 45(5), 810-820.

Lee, Y. and Chao, S.-L. (2009), A neighborhood search heuristic for pre-marshalling export containers, $E u$ ropean Journal of Operational Research, 196(2), 468-475.

Lee, Y. and Hsu, N.-Y. (2007), An optimization model for the container pre-marshalling problem, Computers and Operations Research, 34(11), 3295-3313.

Lee, Y. and Lee, Y.-J. (2010), A heuristic for retrieving containers from a yard, Computers and Operations Research, 37(6), 1139-1147.

Lee, Y. J., Shu, J. H., Lee, J. W., Lee, S. G., and Lee, K. S. (2005), A design of high efficient gantry crane for ultra large container ship, Proceedings of the 16th International Federation of Automatic Control (IFAC) World Congress, Prague, Czech Republic.

Li, W., Goh, M., Wu, Y., Petering, M. E. H., de Souza, R., and $\mathrm{Wu}, \mathrm{Y}$. C. (2012), A continuous time model for multiple yard crane scheduling with last minute job arrivals, International Journal of Production Economics, 136(2), 332-343.

Liu, C.-I., Jula, H., and Ioannou, P. A. (2002), Design, simulation, and evaluation of automated container terminals, IEEE Transactions on Intelligent Transportation Systems, 3(1), 12-26.

Meisel, F. and Bierwirth, C. (2011), A unified approach for the evaluation of quay crane scheduling models and algorithms, Computers and Operations Research, 38(3), 683-693.

Ng, W. C., Mak, K. L., and Zhang, Y. X. (2007), Scheduling trucks in container terminals using a genetic algorithm, Engineering Optimization, 39(1), 33-47.

Nguyen, V. D. and Kim, K. H. (2010), Dispatching ve- hicles considering uncertain handling times at port container terminals, Progress in Material Handling Research: Proceedings of the 11th International Material Handling Research Colloquium, Milwaukee, WI, 210-226.

Paceco Corp. (2012), High productivity dock operations, Hayward, CA, http://www.pacecocorp.com/Engin eering\%20Service\%20\&\%20R\%20\&\%20D/High Productivity_Flyer_p2.pdf.

Park, Y.-M. (2003), Berth and crane scheduling of container terminals, PhD Thesis, Pusan National University.

Park, T., Choe, R., Kim, Y. H., and Ryu, K. R. (2011), Dynamic adjustment of container stacking policy in an automated container terminal, International Journal of Production Economics, 133(1), 385-392.

Roh, H. S. (2011), A scheme to build an automated container transport system (AutoCon) between Seoul and Busan, KOTI World Brief, 3(31), 2-5. http:// www.nowaittransit.com/KOTI World Brief 2011Nov_Vol_3_No_311Excerpt.pdf.

Saanen, Y. (2003), The design and assessment of next generation automated container terminals, Proceedings of 15th European Simulation Symposium, Del$\mathrm{ft}$, Netherlands.

Sauri, S. and Martin, E. (2011), Space allocating strategies for improving import yard performance at marine terminals, Transportation Research Part E: Logistics and Transportation Review, 47(6), 1038-1057.

Siroky, J. (2011), Automatic transhipment systems for container transport in terminals, Perner's Contacts, 3(4), 145-154.

Tian, Y., Yang, B., Fu, H. D., and Yu, J. Z. (2011), Study on equipment scheduling of ZPMC automated container terminal based on improved PSO, Applied Mechanics and Materials, 143/144, 879-884.

Vis, I. F. A. (2006), Survey of research in the design and control of automated guided vehicle systems, European Journal of Operational Research, 170(3), 677709.

Vis, I. F. A. and Carlo, H. J. (2010), Sequencing two cooperating automated stacking cranes in a containner terminal, Transportation Science, 44(2), 169-182.

Vis, I. F. A. and Harika, I. (2004), Comparison of vehicle types at an automated container terminal, $O R$ Spectrum, 26(1), 117-143.

Zhang, C., Chen, W., Shi, L., and Zheng, L. (2010), A note on deriving decision rules to locate export containers in container yards, European Journal of Operational Research, 205(2), 483-485.

Zhao, W. and Goodchild, A. V. (2010), The impact of truck arrival information on container terminal rehandling, Transportation Research Part E: Logistics and Transportation Review, 46(3), 327-343. 